\title{
O PAPEL DA PARCERIA GLOBAL PARA A EDUCAÇÃO NA PROMOÇÃO DOS REFERENTES DA GLOBALIZAÇÃO NOS PLANOS ŞETORIAIS DA EDUCAÇÃO DOS PALOP
}

\author{
EL ROL DE LA ALIANZA MUNDIAL PARA LA EDUCACIÓN EN LA PROMOCIÓN \\ DE LOS REFERENTES DE LA GLOBALIZACIÓN EN LOS PLANES SECTORIALES \\ DE LA EDUCACIÓN DE LOS PAÍSES AFRICANOS DE LENGUA OFICIAL \\ PORTUGUESA
}

\section{THE GLOBAL PARTNERSHIP FOR EDUCATION ROLE IN THE EDUCATION SECTORIAL PAPERS FROM LUSOPHONE AFRICA}

Rui da SILVA ${ }^{1}$

RESUMO: A educação é escolhida como uma prioridade por organizações governamentais e não-governamentais, porque é identificada como um direito humano, mas também como uma estratégia importante para combater a pobreza e promover o crescimento económico. Neste âmbito, a Parceria Global para a Educação é um novo ator que desempenha atualmente um papel importante no financiamento dos sistemas educativos do Sul global. Para tal, estes países tiveram de submeter Planos Setoriais da Educação e satisfazer um certo número de requisitos. Tendo estes pressupostos em mente, o presente artigo pretende inferir em que medida os referentes da globalização na educação estão presentes nos Planos Setoriais da Educação de Cabo Verde, Guiné-Bissau, Moçambique e São Tomé e Príncipe, comparando as suas diferenças e os pontos em comum. Para tal, recorre-se a um corpus documental, para a realização de análise de conteúdo de dados invocados de forma a colocar em evidência o conteúdo manifesto.

PALAVRAS-CHAVE: PALOP. Globalização. Políticas educativas.

RESUMEN: La educación es elegida como una prioridad por las organizaciones gubernamentales y no gubernamentales, porque es identificada como un derecho humano, pero también como una estrategia importante para combatir la pobreza y promover el crecimiento económico. En este marco, la Alianza Mundial Para La Educación es un nuevo actor que desempeña actualmente un papel importante en la financiación de los sistemas educativos del Sur global. Para adherirse a esta financiación, los países tuvieron que someter Planes Sectoriales de la Educación y satisfacer un cierto número de requisitos. En el presente artículo se pretende inferir en qué medida los referentes de la globalización en la educación están presentes en los Planes Sectoriales de Educación de Cabo Verde, Guinea-Bissau, Mozambique y Santo Tomé y Príncipe, comparando las diferencias y los puntos en común. Se recurre a un corpus documental, para la realización de análisis de contenido de datos invocados para poner en evidencia el contenido manifiesto.

${ }^{1}$ Centro de Estudos Africanos da Universidade do Porto (CEAUP), Porto - Portugal. Investigador. ORCID: <https://orcid.org/0000-0003-3369-1285>.E-mail: rdasilva.email@gmail.com 
PALABRAS CLAVE: Países africanos de lengua oficial portuguesa. Globalización. Políticas educativas.

ABSTRACT: Education is chosen as a priority by governmental and nongovernmental organizations because it is identified as a human right, but also as an important strategy to fight poverty and promote economic growth. In this context, the Global Partnership for Education is a new player who currently plays an important role in financing the education systems of the global South. To access to the Global Partnership for Education funds countries need to submit Education Sector Plans and meet a number of requirements.

Taking these assumptions into account, this article intends to infer to what extent the referents of globalization in education are present in the Education Sector Plans of Cape Verde, Guinea-Bissau, Mozambique and São Tomé and Principe, comparing differences and common points between them. Data collection was based on content analysis of a corpus of documents.

KEYWORDS: Lusophone Africa. Globalization. Educational policies.

\section{Introdução}

Tendo como referência o V Seminário Internacional de Pesquisa do Grupo de Estudos e Pesquisas em Política Educacional (GREPPE) com o tema "Dimensões da privatização na Educação Básica" e as políticas educativas viajantes (STEINER-KHAMASI, 2012), o presente texto visa inferir, ainda que de forma exploratória, em que medida a promoção da privatização da educação e dos restantes referentes da globalização na educação estão presentes nos Planos Setoriais da Educação de Cabo Verde, da Guiné-Bissau, de Moçambique e de São Tomé e Príncipe, comparando as suas diferenças e os pontos em comum. São, assim, abordados conceitos como, globalização e transnacionalização da educação e referenciados alguns aspetos da teoria pós-colonial. A premissa fundamenta-se na abordagem da leitura de estudos e de revisão bibliográfica que possibilitou a realização de análise de conteúdo de dados invocados de forma a colocar em evidência o conteúdo manifesto de um corpus documental.

Assim, após uma primeira nota sobre globalização e transnacionalização da educação, por se tornarem relevantes na identificação dos referentes da globalização na educação (SILVA, SANTOS, PACHECO, 2015; SILVA, 2016), a nossa análise centra-se na análise dos Planos Setoriais da Educação de Cabo Verde, da Guiné-Bissau, de Moçambique e de São Tomé e Príncipe. No segmento final que se intitula de considerações finais identificamos as diferenças e os pontos em comum entre os países, bem como as linhas que permitem delinear novas análises. 


\section{Globalização(ões) e transnacionalização da educação}

Podemos considerar a globalização como "um fenómeno multifacetado com dimensões económicas, sociais, políticas, culturais, religiosas e jurídicas interligadas de modo complexo (SANTOS 2002, 32). É um processo cada vez mais descentralizado sentindo-se os seus efeitos em toda a parte, embora em proporções diferentes, não estando sobre a alçada de um punhado de indivíduos, empresas ou estados (GIDDENS, 2005; LITTLE; GREEN, 2009, PACHECO, 2009A). A este respeito, Santos (2002, p. 62) reforça que não existe estritamente uma entidade única chamada globalização; este termo só deveria ser usado no plural, uma vez que existem globalizações. No entanto, deve-se ter em atenção que as globalizações envolvem conflitos e, por isso vencedores e vencidos. Este facto leva a que ocorra com elevada frequência que o discurso sobre a globalização é a história dos vencedores contada pelos próprios.

No que concerne à educação, esta sofre influências da globalização, essencialmente do modelo neoliberal dominante sendo, portanto, uma globalização hegemónica (SANTOS, 2002, 2006; DALE; ROBERTSON, 2004). Tendo este pressuposto em mente, cada Estado segue uma agenda globalmente estruturada (DALE, 2004) e estamos perante a existência de políticas educativas globais (PEG) (ROBERTSON, 2012; VERGER et al., 2012).

Os países do Sul global, como é o caso dos países que são analisados no presente artigo, comparativamente ao do Norte global, possuem uma intensidade superior de influências globais. Este facto está relacionado com uma grande dependência de ajuda externa em diferentes modalidades, como, por exemplo, em termos de financiamento, informação e de especialistas (VERGER et al., 2012). Estes mecanismos de poder/ autoridade originam uma redução da capacidade deste Estados dirigem os seus sistemas educativos (CROSSLEY, 2001; WILLIAMS, 2009; BALL, 2012). Assim, a política educativa tal como a conhecíamos foi alterada, mas também a forma como pensamos e estudamos estas políticas, pois as organizações internacionais (e.g. OCDE, OIT, UNESCO UNICEF, Banco Mundial), são agentes políticos relevantes na governação da educação (ROBERTSON, 2012; VERGER et al., 2012). Estas organizações internacionais dependem mais de uns Estados do que outros, uma vez que só têm o poder que lhes conferem os Estados que as sustentam, pois são uma criação direta dos Estados e dependem do seu financiamento para funcionar (CHARLOT, 2007). A nível mundial há várias organizações multilaterais (internacionais ou regionais) e bilaterais e não-governamentais que têm uma influência crescente em vários domínios, e claro 
está, também na educação, pois esta foi definida como uma estratégia de desenvolvimento dos países, de combate à pobreza e um direito humano (HARBER, 2014).

Deste modo, podemos afirmar que organizações com várias tipologias e mandatos veiculam em muitas partes do mundo reformas educativas e um conjunto de políticas educativas similares, surgindo reformas viajantes que se instalam nos sistemas educativos e provocam alterações (STEINER-KHAMSI, 2012).

Em termos globais a OCDE e o Banco Mundial, nas últimas duas décadas, são as organizações que se destacam na promoção dos benefícios da educação para os bons resultados económicos (BONAL; RAMBLA, 2009). Consequentemente, podem ser consideradas como as organizações mais influentes a nível global na definição de agendas e prioridades na área da educação. Devido a possuírem matrizes diferentes, a OCDE foca a sua atenção nos países considerados ricos e o Banco Mundial nos considerados pobres.

Neste quadro, surge a Parceria Global para a Educação (PGE) que traz estes princípios, mas com uma nova roupagem. Esta é uma parceria multi-stakeholders que inclui como membros doadores, governos dos países receptores de ajuda ao desenvolvimento, agências das Nações Unidas, organizações não-governamentais (ONGs), fundações e empresas (GPE, 2017). No momento de escrita, a Parceria Global para a Educação apoia 65 países priorizando os mais pobres, vulneráveis e aqueles considerados países frágeis ou afetados por conflito, estes últimos representando cerca de metade dos países apoiados (GPE, 2017). O apoio da PGE implica o cumprimento de vários requisitos, entre eles a elaboração de um plano setorial da educação. Apesar de haver a participação de toda esta tipologia de instituições, o Banco Mundial ou o UNICEF assumem na maioria dos casos um papel de destaque na sua implementação ao nível dos países, particularmente nos considerados países frágeis ou afetados por conflito, onde as instituições governamentais e os serviços do estado estão anémicos.

Os Países Africanos de Língua Oficial Portuguesa (PALOP) que têm apoio da PGE são Cabo Verde (em processo de adesão), Guiné-Bissau (desde 2010), Moçambique (desde 2003) e São Tomé e Príncipe (desde 2007).

\section{Referentes da globalização na educação}

Apesar de termos tentado definir o termo globalização, concordamos com Pacheco (2009) quando afirma que o mais importante é conhecer como a globalização funciona e não 
funciona, ao invés do que ela é. Por esta razão, a seguir apresentamos os referentes da globalização na educação, que pretendem sistematizar e realizar uma súmula do que narra a literatura da influência da globalização(ões) na educação ${ }^{2}$. Estes referentes produzidos e publicados no âmbito de trabalhos anteriores do autor, constituem um marco importante para este artigo, uma vez que são a componente que permitiu a criação de categorias para a análise de conteúdo realizada.

Referentes da globalização na educação:

- $\quad$ Centralidade do currículo como veículo de conhecimento;

- Currículo valorizado como um recurso económico;

- $\quad$ Cada estado segue uma agenda globalmente estruturada;

- $\quad$ Foco em padrões de eficiência e qualidade;

- $\quad$ Privatização de serviços;

- Tendência para a homogeneização dos sistemas educativos, essencialmente no contexto/nível de decisão curricular político-administrativo;

- $\quad$ Convergência para a existência de um core curriculum;

- $\quad$ Retylerização das práticas curriculares;

- Reforço dos conteúdos e das competências;

- $\quad$ Foco na avaliação performativa e estandardizada (testes de âmbito nacional);

- Discursos políticos a colocar ênfase na descentralização e termos de reforma;

- Foco na individualização, no reforço do local e em noções de identidade, diversidade e projeto;

- Introdução de conceitos-chave, tais como:

○ Qualidade;

- Prestação de contas;

- Aprendizagem ao longo da vida;

- Economia do conhecimento;

○ Competência;

○ Eficiência.

- $\quad$ Enfase na busca de qualidade e eficiência impulsionadas através de boas práticas;

- Fragmentação do conhecimento escolar dando mais peso curricular a certas disciplinas como, por exemplo, a Matemática e as Ciências;

${ }^{2}$ Para mais pormenores sobre os referentes da globalização na educação ver: Silva, Santos, Pacheco (2015); Silva (2016). 
- Balcanização do conhecimento escolar, colocando ênfase numa organização curricular insular;

- Importância dada a temas como educação para a cidadania e competências para a vida.

\section{Metodologia}

O presente artigo tem por base a análise documental (de documentos primários) por ser considerada uma técnica não interferente nos estudos de ciências sociais (LEE, 2003).

Os documentos utilizados podem ser classificados como textos políticos (OZGA, 2000), caracterizando-se como dados preexistentes, sendo realizada uma utilização textual dos mesmos (QUIVY; CAMPENHOUDT, 2005). A análise centra-se nos Planos Setoriais da Educação produzidos pelos Governos de Cabo Verde, da Guiné-Bissau, de Moçambique e de São Tomé e Príncipe (apesar de alguns serem elaborados com o apoio de consultores de organizações internacionais).

Partiu-se de uma análise categorial do conteúdo baseada num sistema pré-definido, seguindo desta forma um procedimento fechado devido às categorias emergirem do quadro teórico, neste caso dos referentes da globalização na educação identificados anteriormente (BARDIN, 2007, ESTEVES, 2006).

No quadro I estão representadas as categorias, os referentes e a respetiva codificação.

\section{Quadro 1 - Categorias e referentes}

\begin{tabular}{|c|c|}
\hline Categorias & Referentes \\
\hline $\begin{array}{l}\text { A - Centralidade do currículo como } \\
\text { veículo de conhecimento }\end{array}$ & $\begin{array}{l}\text { A1 - O currículo é evocado como resposta aos problemas sociais e } \\
\text { económicos; } \\
\text { A3 - O currículo é valorizado como um recurso económico; } \\
\text { A3 - Principal função da educação é a formação de trabalhadores. }\end{array}$ \\
\hline B - Privatização de serviços & $\begin{array}{l}\text { B1 - Valorização da iniciativa privada; } \\
\text { B2 - Direito de escolha; } \\
\text { B3 - Evocação da educação como um serviço público de gestão } \\
\text { privada; } \\
\text { B4 - Diminuição da interferência do estado; }\end{array}$ \\
\hline
\end{tabular}




C - Tendência para a homogeneização
dos sistemas educativos

a

C1 - Organização do sistema educativo próxima dos países ocidentais (ciclos de ensino, idade escolar, modelo de sala de aula, organização curricular).

D1 - Evocação da necessidade de descentralização;

D2 - Evocação da necessidade/importância da reforma educativa;

D3 - Incentivo à utilização de turmas multi-classe e trabalho por turnos.

E1 - Valorização da qualidade;

E2 - Evocação de termos importados do mundo económico (e.g. competitividade, eficácia, eficiência, performance, benchmarking);

E3 - Evocação de uma abordagem por competências e reforço dos conteúdos;

E4 - Evocação da aprendizagem ao longo da vida;

E5 - Definição das funções atribuídas à educação e aos diferentes atores;

E6 - Foco na educação obrigatória e na educação das meninas.

F1 - Evocação da avaliação estandardizada e performativa;

F - Retylerização das práticas

F2 - Evocação de testes/exames de âmbito nacional para os alunos;

F3 - O currículo é definido como um plano;

F4 - O currículo é normativo e definido pela Administração Central;

F5 - O currículo é definido pelos resultados.

G1 - Organização curricular insular (disciplinas) - destaque para disciplinas como a matemática, a língua portuguesa, a língua inglesa, o empreendedorismo e as TIC;

G2 - Organização curricular conectiva (competências) - destaque para as competências para a vida e a educação para a cidadania.

Fonte: Autor

\section{Análise e discussão dos dados}

No quadro II podemos observar a frequência das unidades de registo por categoria e por referente, e no gráfico 1 o número total de unidades de numeração por categoria e por país. Da observação destes, tendo em consideração todos os países, podemos constatar que a categoria com mais unidades de registo é a E - Cada Estado segue uma agenda globalmente estruturada [54]. Os referentes com mais unidades de registo são o E1 - Valorização da qualidade [20] e a E2 - Evocação de termos importados do mundo económico (e.g. competitividade, eficácia, eficiência, performance, benchmarking) [30]. 
Gráfico 1 - unidades de registo por categoria e por país

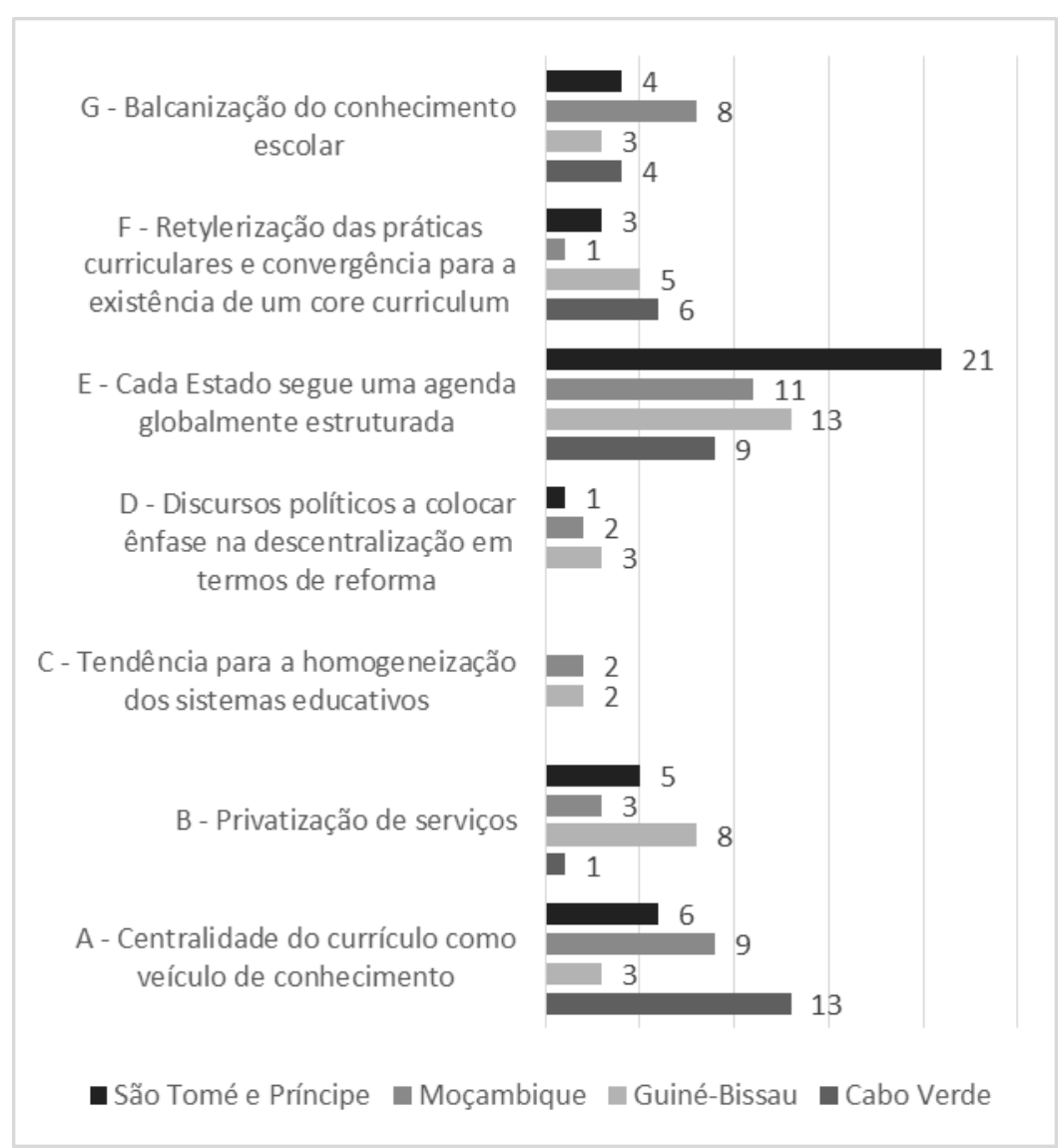

Fonte: Autor

Os seguintes excertos dos documentos permitem observar alguns exemplos dos referentes E1 e E2:

Melhorar a gestão e pilotagem do sistema educativo, através da alocação optimal dos recursos, implementação de medidas que permitam a transformação dos recursos em resultados por parte dos alunos [GuinéBissau]

O sector da educação constitui a primeira prioridade orçamental do governo Santomense. Em 2010, o Estado atribuiu 38,4\% das suas despesas correntes a este sector. Recorde-se que a média africana situa-se em $22 \%$. [São Tomé e Príncipe]

Em termos de comparações internacionais, este rácio é extremamente elevado, indicando um número "excessivo" de não docentes (nomeadamente nas delegações locais da educação) no país. Estima-se que, com base na referência internacional (média do que é observado em países comparáveis), a economia potencial seria da ordem de 470 milhões de CVE. [Cabo Verde] 
Esta revisão deverá ser feita numa perspectiva de preparação para um ensino básico de 9 a 10 anos, bem como, de maior eficácia e eficiência no uso dos recursos necessários para a sua implementação em termos de professores, infra-estruturas, equipamentos e material didáctico. [Moçambique]

As razões que parecem estar inerentes a estes referentes terem um maior número de unidades de numeração são o foco na educação de qualidade para todos. No que diz respeito ao referente E2 que trata os termos importados do mundo económico, denotamos que há uma forte presença de um discurso impregnado de um léxico do mundo económico (ex. racionalização, eficácia, eficiência, performance), com as palavras eficácia, eficiência e a definição de benchmarking a surgirem com maior frequência. Logo, este aspeto parece indicar que esta terminologia está a ganhar o seu espaço no léxico do discurso educativo, tornando-se progressivamente o seu esqueleto.

O benchmarking, em particular, parece-nos que potencia as comparações entre países tendo em consideração aspetos meramente estatísticos tratando os países como entidades homogéneas. Na narrativa dos documentos verificamos a existência do uso frequente do benchmarking com o continente africano, com os dados internacionais e com os países comparáveis - apesar de não ser possível perceber quais os critérios tidos em consideração para as diferentes escolhas de benchmarking e o quais os critérios para serem considerados países comparáveis.

Desta forma, os dados parecem indicar que os pressupostos inerentes a cada estado seguem uma agenda globalmente estruturada são uma caraterística presente em Cabo Verde, na Guiné-Bissau, em Moçambique e em São Tomé e Príncipe. Contudo, não devemos descurar que a educação para todos é um aspeto que reúne consenso entre os doadores e os governos. A educação para todos é uma prioridade comum a todos estes países que remonta às lutas de libertação e às prioridades desde a independência do jugo colonial de Portugal.

As categorias (ver Apêndice 1) que apresentam um número menor de unidades de numeração são a C - Tendência para a homogeneização dos sistemas educativos [4] e a D Discursos políticos a colocar ênfase na descentralização em termos de reforma [6]. Assim, as questões inerentes à descentralização dos sistemas educativos, ao trabalho por turnos e à ênfase nas reformas educativas são menos expressivas nos documentos tendo aparentemente, uma menor importância para os países no planeamento mais macro.

Apesar da categoria E - Cada Estado segue uma agenda globalmente estruturada, ser, de forma global, a que tem mais unidades de numeração, quando analisamos o gráfico 1 verificamos que não é a categoria com mais unidades de numeração no caso de Cabo Verde. 
A categoria com mais unidades de numeração para este país é a, A - Centralidade do currículo como veículo de conhecimento, e de forma mais específica o referente A3 - Principal função da educação é a formação de trabalhadores. Este aspeto parece estar relacionado com o alcance por parte de Cabo Verde da maioria dos aspetos referentes à universalização do ensino básico e do sistema educativo apresentar desafios diferentes dos restantes países. No documento de Cabo Verde as referências à formação de capital humano e de acesso ao emprego parecem constituir a matriz estratégica e a espinha dorsal do documento. Os seguintes estratos espelham este aspeto:

Com base nos resultados do diagnóstico, vários elementos são considerados centrais para orientar a visão do país em matéria de produção do capital humano pertinente, em quantidade e qualidade, para acompanhar as perspectivas macroeconómicas nacionais para o crescimento e o emprego. [Cabo Verde]

Com efeito, esta articulação é indispensável para o objetivo de que todos os jovens saídos do ensino geral possam beneficiar efetivamente de uma preparação apropriada para o acesso ao emprego. [Cabo Verde]

Ainda no que se refere à categoria $\mathrm{A}$ - Centralidade do currículo como veículo de conhecimento, verificamos também que no caso de Moçambique há 9 unidades de numeração, dando relevo aos referentes A1 - O currículo é evocado como resposta aos problemas sociais e económicos e A3 - Principal função da educação é a formação de trabalhadores. Estes resultados parecem indicar que a educação é vista de forma bastante instrumental, sendo um veículo para responder aos desafios económicos e sociais.

No que concerne à categoria $\mathrm{B}$ - Privatização de serviços, verificamos que parece ter maior expressividade na Guiné-Bissau e em São Tomé e Príncipe, com um discurso bastante otimista em relação a esta perspectiva, quando a investigação (LEWIN, 2007; WALFORD; SRIVASTAVA, 2007; SRIVASTAVA, 2013; HÄRMÄ, 2016; VERGER et al., 2016), mesmo a do Banco Mundial (BANCO MUNDIAL, 2018) - grande promotor do setor privado - indica que não há evidências consistentes que os provedores privados de educação nos países do Sul global permitem o alcance de melhores resultados escolares, em comparação com os provedores públicos. No documento de Cabo Verde estes aspetos da privatização têm pouca expressão, aparecendo apenas uma referência, e diz respeito ao ensino superior.

Os seguintes trechos ilustram este aspecto:

Acrescer o papel do sector privado na oferta educativa, particularmente a nível do ensino secundário e ensino superior [Guiné-Bissau] 
Crescimento da oferta privada de 10\% por ano [Guiné-Bissau]

Melhoria da oferta do ensino privado através de medidas de incentivo (10\% do custo unitário do aluno do sector público por aluno do sector privado), (...) A efectivação destas medidas será possivel através de um acordo contratual entre as escolas concernentes e o Estado, no qual elas comprometer-se-ão, em troca do apoio prestado, a diminuir os custos de escolarização, reservar vagas gratuitas para os alunos mais carenciados e melhorar a qualidade das aprendizagens. [Guiné-Bissau]

Em STP, a intervenção do sector privado na oferta educativa é ainda fraca, apesar de existir uma forte demanda, particularmente no pré-escolar, Ensino Secundário e na formação técnico-profissional. [São Tomé e Príncipe]

Estimular a oferta do ensino privado de qualidade, através da implementação de medidas de carácter económico e institucional realmente atractivas. [São Tomé e Príncipe]

Do estímulo da oferta do ensino privado, implementando medidas de carácter económico e institucional atractivas, nomeadamente a formação e capacitação de seus professores, fornecimentos de manuais e equipamentos escolares, obtendo-se, em contrapartida que o privado baixe o custo da escolarização para as famílias e melhore a qualidade de aprendizagem [São Tomé e Príncipe]

O ensino particular é a opção para expandir o nível secundário, não apenas nas cidades, mas também nas regiões distantes dos centros urbanos. As ONGs e instituições religiosas podem ser parceiras importantes do Governo neste processo. Neste sentido, serão criadas condições para encorajar uma maior contribuição do ensino particular. [Moçambique]

Em relação à categoria $\mathrm{F}$ - Retylerização das práticas curriculares e convergência para a existência de um core curriculum, Cabo Verde e Guiné-Bissau apresentam o maior número de unidades de numeração, destacando-se os referentes F1 - Evocação da avaliação estandardizada e performativa e F2 - Evocação de testes/exames de âmbito nacional para os alunos. Verificamos nos documentos que as questões relacionadas com a avaliação estandardizada e os exames de âmbito nacional parecem ser uma preocupação. Este aspeto está alinhado com a atual pressão internacional para os países terem um conjunto de indicadores iguais sobre o sistema educativo para a monitorização no âmbito dos Objetivos de Desenvolvimento Sustentável, em particular o objetivo 4 - Garantir uma educação inclusiva e equitativa de qualidade e promover oportunidades de aprendizagem ao longo da vida para todos, e para monitorizarem se os objetivos definidos estão ou não a ser cumpridos.

Os seguintes trechos ilustram este aspecto: 
A primeira disposição consiste em organizar, desde o acesso ao $7 .^{\circ}$ ano de escolaridade a uma avaliação de largo espectro de todos os recém-chegados tanto em matemática como em português. [Cabo Verde]

Um dispositivo externo de avaliação de natureza sumativa será, aliás, introduzido e aplicado de forma regular para avaliar os resultados alcançados. Nesta fase, não se trata de observar apenas sucessos ou deficiências a nível das escolas, mas de identificar e de pôr em prática as medidas a tomar para resolver as dificuldades que tenham sido constatadas. [Cabo Verde]

o Ministério da Educação procederá a uma modernização dos procedimentos de gestão dos exames do ensino básico e do secundário, bem como o reforço de controlos contínuos. [Guiné-Bissau]

Quando analisamos os dados referentes à categoria $\mathrm{G}$ - Balcanização do conhecimento escolar, verificamos que o maior número de unidades de numeração surge relacionada com uma organização curricular insular, isto é, uma organização por disciplinas com destaque para disciplinas como a matemática, a língua portuguesa, a língua inglesa, o empreendedorismo e as TIC. Este aspeto reforça o que verificamos na categoria F, pois o foco nos exames de âmbito nacional pressupõe uma maior ênfase na organização por disciplinas, logo uma organização curricular insular. Contudo, o referente G2 - organização curricular conectiva (competências) - também surge destacado, estando este facto relacionado com a perspectiva mais instrumental da educação, principalmente no que se refere à abordagem das competências para a vida e à educação para a cidadania e para a paz.

Os seguintes trechos ilustram este aspecto:

O segundo aspeto das grandes orientações consiste em rever, no ensino básico, os conteúdos do programa e os horários das disciplinas nas formações ministradas. Isto assumirá duas formas complementares, a saber i) fazer uma certa recentragem em torno das disciplinas fundamentais, nomeadamente proporcionando mais tempo de aprendizagem efetiva para matemática e português e ii) focalizar as abordagens de aprendizagem na articulação entre os aspetos formais e os aspetos funcionais (reforçar o sentido da escrita tanto em compreensão como de expressão, de formatação e resolução de problemas...). [Cabo Verde]

A introdução das Tecnologias de Informação e Comunicação, aliada com a infraestruturação das escolas e com as reformas necessárias no sistema de ensino, é um factor chave para a melhoria da qualidade do ensino e para o desenvolvimento institucional, sendo uma aposta que já começou a acontecer nos países mais desenvolvidos e que, nos próximos anos, se alastrará a todo o mundo. [Moçambique]

Esta programação por nível de ensino, enquadrada em três grandes objectivos, implica que os temas transversais (HIV e SIDA, Género, Saúde Escolar, etc.), os programas específicos (desporto escolar, alimentação escolar, etc.) e as áreas programáticas (formação de professores, 
construção, provisão do livro escolar e materiais didácticos, ensino à distância, entre outras) sejam tratados numa perspectiva transversal. [Moçambique]

Promover e melhorar a alimentação e saúde escolar e desenvolver os comportamentos cívicos relativos à paz e aos direitos humanos. [GuinéBissau]

Utilizar as Tecnologias de Informação e Comunicação (TIC) como instrumento base de desenvolvimento do sistema educativo (válido para todos os ciclos). [São Tomé e Príncipe]

Posto isto, verificamos que os referentes da globalização na educação estão presentes nestes documentos estratégicos dos diferentes países, destacando-se as seguintes:

- Currículo valorizado como um recurso económico;

- $\quad$ Cada estado segue uma agenda globalmente estruturada;

- $\quad$ Foco em padrões de eficiência e qualidade;

- Reforço dos conteúdos e das competências;

- $\quad$ Enfase na busca de qualidade e eficiência impulsionadas através de boas práticas;

- Balcanização do conhecimento escolar, colocando ênfase numa organização curricular insular;

- $\quad$ Foco na avaliação performativa e estandardizada (testes de âmbito nacional);

- Introdução de conceitos-chave, tais como:

○ Qualidade;

○ Prestação de contas;

○ Aprendizagem ao longo da vida;

○ Economia do conhecimento;

○ Competência;

○ Benchmarking;

○ Eficiência.

Neste processo de elaboração dos documentos, a PGE, mesmo que aparentemente de forma indireta, desempenhou um papel central neste processo. Apesar da autoria dos documentos ser atribuída aos governos dos diferentes países, na sua elaboração houve a participação de vários consultores internos e externos que moldaram o conteúdo e a forma das estratégias definidas. Não devemos também deixar de ter em consideração que como se trata de documentos de acesso a financiamento, crucial para o funcionamento dos sistemas 
educativos dos países, há sempre condicionalismos explícitos e implícitos. Porém, não demos descurar o facto que as pessoas nas periferias não são atores passivos, são ao mesmo tempo criadores e intérpretes, produzindo, assim, um terceiro espaço (GEORGE; LEWIS, 2011). Desta forma, este processo de construção dos documentos assemelha-se a uma dança entre perspectivas internas e externas onde um bailarino assume sempre uma maior preponderância na forma como se dança, neste caso o externo.

\section{Considerações finais}

No presente artigo tentamos demonstrar quais os referentes da globalização na educação que estão presentes nos Planos Setoriais da Educação de Cabo Verde, da GuinéBissau, de Moçambique e de São Tomé e Príncipe, comparando as diferenças e os pontos em comum. Seria simplista concluir que as organizações presentes na Parceria Global pela Educação, principalmente a agência que lidera os processos nos países, são os únicos responsáveis pela promoção destes referentes, principalmente da categoria E - Cada Estado segue uma agenda globalmente estruturada. Os vários atores nacionais e os próprios governos também desempenham este papel.

No que concerne, por exemplo, à promoção da educação para todos, este aspeto reúne consenso entre os doadores e os governos de todos os países em análise, sendo que a educação para todos é uma prioridade que remonta às lutas de libertação e atravessa os países até à atualidade. Porém, devido às cartas políticas do setor educativo serem um dos requisitos para aceder ao financiamento da Parceria Global pela Educação, há sempre condicionalismos.

Assistimos também a uma presença de um conjunto de termos importados do mundo económico com preponderância para as palavras qualidade, eficiência e aspetos que remetem para o benchmarking. Assim, podemos concluir que esta terminologia está a ganhar espaço, tendo a transformar-se no centro do discurso educativo.

Os dados indicam que as questões inerentes à descentralização dos sistemas educativos, ao trabalho por turnos e à ênfase nas reformas educativas não são aspetos muito presentes nos documentos analisados, consequentemente menos relevantes em termos estratégicos, pelo menos no discurso político dos documentos analisados.

No caso de Cabo Verde, verificamos que aspetos relacionados com o papel da educação como fator primordial para a formação de capital humano e de acesso ao emprego são a matriz estratégica do documento, sendo esta identificada como uma estratégia para 
solucionar desafios económicos e sociais do país. Este aspeto também está bastante presente no caso de Moçambique.

As questões inerentes à privatização de serviços aparecem com maior expressividade na Guiné-Bissau e em São Tomé e Príncipe, sendo que no caso de Cabo Verde apenas verificamos uma unidade de numeração referente ao ensino superior. Os documentos da Guiné-Bissau e de São Tomé e Príncipe apresentam mesmo uma perspectiva bastante otimista em relação à importância e à necessidade de aumentar a oferta privada de educação, indo ao encontro da tendência global do momento.

A pressão global para os países terem em funcionamento um sistema de recolha de dados para monitorizar o sistema educativo baseado em testes/exames estandardizados de âmbito nacional, parece estar espelhada nas unidades de registo da categoria F. Este aspeto está relacionado com a monitorização dos planos nacionais que confluem para o objetivo 4 dos Objetivos de Desenvolvimento Sustentável - Garantir uma educação inclusiva e equitativa de qualidade e promover oportunidades de aprendizagem ao longo da vida para todos.

No que concerne à organização curricular conectiva e insular, há evidências que mostram uma tendência para a sua ocorrência em simultâneo, parecendo sobressair a organização curricular insular. Estes aspetos parecem estar relacionados com as questões inerentes à monitorização do sistema educativo baseado em testes/exames estandardizados de âmbito nacional, como referido anteriormente, e a educação ser vista como um meio para a solução de problemas sociais e económicos.

AGRADECIMENTOS: O autor gostaria de agradecer ao Grupo de Estudos e Pesquisas em Política Educacional (GREPPE) terem possibilitado a sua presença V Seminário Internacional de Pesquisa com o tema "Dimensões da privatização na Educação Básica" que foi o letmotiv para a escrita do presente artigo.

\section{REFERÊNCIAS}

BALL, S. J. Global education inc: new policy networks and the neo-liberal imaginary. Londres: Routledge, 2012. 169 p.

BANCO MUNDIAL. World Development Report 2018: Learning to Realize Education's Promise. Washington: Banco Mundial, 2018. 240 p. 
CARSON, T. R. Re-thinking Curriculum Change from the Place of the Teacher. In: ROPO, E. e AUTIO, T. (Org.). International conversations on curriculum studies: subject, society and curriculum. Roterdão: Sense Publishers, p. 213-224, 2009.

CROSSLEY, M. Cross-cultural issues, small states and research: capacity building in Belize. International Journal of Educational Development, v. 21, n. 3, p. 217-229, 2001.

DALE, R. Globalização e educação: demonstrando a existência de uma "Cultura Educacional Mundial Comum" ou localizando uma "Agenda Globalmente Estruturada para a Educação"? Educação \& Sociedade, Campinas, v. 25, p. 423-460, 2004.

GEORGE, J.; LEWIS, T. Exploring the global/local boundary in education in developing countries: the case of the Caribbean. Compare: A Journal of Comparative and International Education, v. 41, n. 6, p. 721-734, 2011.

HARBER, C. Education and international development: theory, practice and issues. Oxford: Sympsium Books, 272 p., 2014.

HÄRMÄ, J. Is there a private schooling market in poor neighbourhoods in Maputo, Mozambique? Exploring the role of the non-state education sector. Oxford Review of Education, v. 42, n. 5, p. 511-527, 2016.

LEWIN, K. M. The Limits to Growth of Non-government Private Schooling in Sub-Saharan Africa. In: SRIVASTAVA, P.; WALFORD, G. (Org.). Private schooling in less economically developed countries: Asian and African perspectives. Oxford: Symposium Books, 41-63 p., 2007.

PACHECO, J. A. Whole, bright, deep with understanding: life story and politics of curriculum studies: in-between William Pinar and Ivor Goodson. Roterdão: Sense Publishers, 169 p., 2009.

ROBERTSON, S. L. Researching Global Education Policy: Angles In/Oun/Out... In: VERGER, A.; NOVELLI, M.; et al. (Org.). Global education policy and international development: New agendas, issues and policies. Londres: Bloomsbury Academic, 33-51 p., 2012.

SRIVASTAVA, P. Low-fee Private Schooling: issues and evidence. In: SRIVASTAVA, P. (Org.). Low-fee private schooling: Aggravating equity or mediating disadvantage? Oxford: Symposium Books, 7-35p., 2013.

STEINER-KHAMSI, G. Understanding policy borrowing and lending. Building comparative policy studies. In: STEINER-KHAMSI, G. e WALDOW, F. (Org.). World yearbook of education 2012. Policy borrowing and lending in education. Londres: Routledge, 5-17 p., 2012.

VERGER, A.; FONTDEVILA, C.; ZANCAJO, A. The privatization of education: a political economy of global education reform. Nova York: Teachers College Press, 2016. 224 p. 
VERGER, A.; NOVELLI, M.; ALTINYELKEN, H. K. Global education policy and international development: an introductory framework. In: VERGER, A.; NOVELLI, M.; et al (Org.). Global education policy and international development: New agendas, issues and policies. Londres: Bloomsbury Academic, 2012. p. 3-31.

WALFORD, G.; SRIVASTAVA, P. Examining Private Schooling in Less Economically Developed Countries: Key issues and new evidence. In: SRIVASTAVA, P.; WALFORD, G. (Org.). Private Schooling in Less Economically Developed Countries: Asian and African perspectives. Oxford: Symposium Books, 2007. p. 7-14 p.

WILLIAMS, L. Globalisation of Education Policy: Its Effects on Developing Countries. In: ZAJDA, J.; RUST, V. (Org.). Globalisation, policy and comparative research. Discourses of globalization: Springer Netherlands, 2009. 77-92 p.

\section{Como referenciar este artigo}

SILVA, Rui da. O papel da Parceria Global para a Educação na promoção dos referentes da globalização nos Planos Setoriais da Educação dos PALOP. Revista on line de Política e Gestão Educacional, Araraquara, v. 22, n. esp. 3, p. 1258-1275, dez., 2018 ISSN: 15199029. DOI: 10.22633/rpge.v22iesp3.12010

Submetido em: $10 / 10 / 2018$

Aprovado em: 16/11/2018 


\section{APÊNDICE 1}

Quadro 2: Frequência das Unidades de Registo

\begin{tabular}{|c|c|c|c|c|c|c|c|c|c|}
\hline \multirow{3}{*}{ Categorias } & \multicolumn{3}{|c|}{ Cabo Verde } & \multicolumn{2}{|c|}{ Guiné-Bissau } & \multicolumn{2}{|c|}{ Moçambique } & \multicolumn{2}{|c|}{ São Tomé e Príncipe } \\
\hline & \multicolumn{3}{|c|}{ Unidades de Numeração } & \multicolumn{2}{|c|}{$\begin{array}{ll}\text { Unidades } & d e \\
\text { Numeração } & \end{array}$} & \multicolumn{2}{|c|}{ Unidades de Numeração } & \multicolumn{2}{|c|}{ Unidades de Numeração } \\
\hline & \multicolumn{2}{|c|}{ por referente } & $\begin{array}{l}\text { por } \\
\text { categoria }\end{array}$ & $\begin{array}{l}\text { por } \\
\text { referente }\end{array}$ & $\begin{array}{l}\text { por } \\
\text { categoria }\end{array}$ & $\begin{array}{l}\text { por } \\
\text { referente }\end{array}$ & $\begin{array}{l}\text { por } \\
\text { categoria }\end{array}$ & $\begin{array}{l}\text { por } \\
\text { referente }\end{array}$ & $\begin{array}{l}\text { por } \\
\text { categoria }\end{array}$ \\
\hline \multirow{3}{*}{$\begin{array}{l}\text { A - Centralidade do currículo como veículo de } \\
\text { conhecimento }\end{array}$} & A1 - & 1 & \multirow{3}{*}{13} & 2 & \multirow{3}{*}{3} & 3 & \multirow{3}{*}{9} & 2 & \multirow{3}{*}{6} \\
\hline & $A 2$ - & $\mathbf{0}$ & & $\mathbf{0}$ & & $\mathbf{0}$ & & $\mathbf{0}$ & \\
\hline & $A 3$ - & 2 & & 1 & & 6 & & 4 & \\
\hline & & & & & & & & & \\
\hline \multirow{4}{*}{ B - Privatização de serviços } & B1 - & $\mathbf{0}$ & \multirow{4}{*}{1} & 7 & \multirow{4}{*}{8} & 2 & \multirow{4}{*}{3} & 4 & \multirow{4}{*}{5} \\
\hline & B2 - & $\mathbf{0}$ & & $\mathbf{0}$ & & $\mathbf{0}$ & & $\mathbf{0}$ & \\
\hline & B3 - & 1 & & 1 & & $\mathbf{0}$ & & 1 & \\
\hline & B4 - & $\mathbf{0}$ & & $\mathbf{0}$ & & 1 & & $\mathbf{0}$ & \\
\hline $\begin{array}{l}\text { C - Tendência para a homogeneização dos } \\
\text { sistemas educativos }\end{array}$ & C1 - & $\mathbf{0}$ & $\mathbf{0}$ & 2 & 2 & 2 & 2 & $\mathbf{0}$ & $\mathbf{0}$ \\
\hline & & & & & & & & & \\
\hline \multirow{3}{*}{$\begin{array}{l}\text { D - Discursos políticos a colocar ênfase na } \\
\text { descentralização em termos de reforma }\end{array}$} & D1 - & $\mathbf{0}$ & \multirow{3}{*}{$\mathbf{0}$} & 1 & \multirow{3}{*}{3} & 2 & \multirow{3}{*}{2} & 1 & \multirow{3}{*}{1} \\
\hline & D2 - & $\mathbf{0}$ & & $\mathbf{0}$ & & $\mathbf{0}$ & & $\mathbf{0}$ & \\
\hline & D3 - & $\mathbf{0}$ & & 2 & & $\mathbf{0}$ & & $\mathbf{0}$ & \\
\hline \multirow{6}{*}{$\begin{array}{l}\text { E - Cada Estado segue uma agenda globalmente } \\
\text { estruturada }\end{array}$} & E1 - & 0 & \multirow{6}{*}{9} & 5 & \multirow{6}{*}{3} & 6 & \multirow{6}{*}{11} & 9 & \\
\hline & E2 - & 9 & & 6 & & 3 & & 12 & \\
\hline & E3 - & $\mathbf{0}$ & & $\mathbf{0}$ & & $\mathbf{0}$ & & $\mathbf{0}$ & 0 \\
\hline & E4 - & $\mathbf{0}$ & & $\mathbf{0}$ & & $\mathbf{0}$ & & $\mathbf{0}$ & 21 \\
\hline & E5 - & $\mathbf{0}$ & & $\mathbf{0}$ & & $\mathbf{0}$ & & $\mathbf{0}$ & \\
\hline & E6 - & $\mathbf{0}$ & & 2 & & 2 & & $\mathbf{0}$ & \\
\hline & & & & & & & & & \\
\hline & F1 - & 3 & & 2 & & $\mathbf{0}$ & & 1 & \\
\hline F - Retylerização das práticas curriculares e & F2 - & 3 & & 3 & & 1 & & 1 & \\
\hline convergência para a existência de um core & F3 - & $\mathbf{0}$ & 6 & $\mathbf{0}$ & 5 & $\mathbf{0}$ & 1 & $\mathbf{1}$ & 3 \\
\hline curriculum & F4 - & $\mathbf{0}$ & & $\mathbf{0}$ & & $\mathbf{0}$ & & $\mathbf{0}$ & \\
\hline & F5 - & $\mathbf{0}$ & & $\mathbf{0}$ & & $\mathbf{0}$ & & $\mathbf{0}$ & \\
\hline & G1 - & 4 & & 0 & & 4 & & 2 & \\
\hline G - Balcanização do conhecimento escolar & G2 - & $\begin{array}{l}4 \\
0\end{array}$ & 4 & $\frac{0}{3}$ & 3 & $\frac{4}{4}$ & 8 & $\frac{2}{2}$ & 4 \\
\hline
\end{tabular}

RPGE- Revista on line de Política e Gestão Educacional, Araraquara, v. 22, n. esp. 3, p. 1258-1275, dez., 2018 ISSN: 1519-9029. 